\section{El banco del frente, del lado o el de más allá}

La competencia acchilenos no significa un mejor mercado para los consumidores de productos financieros. Y la Super de bancos parece estar sufriendo un síndrome de Estocolmo.

Por Claudio Agostini*

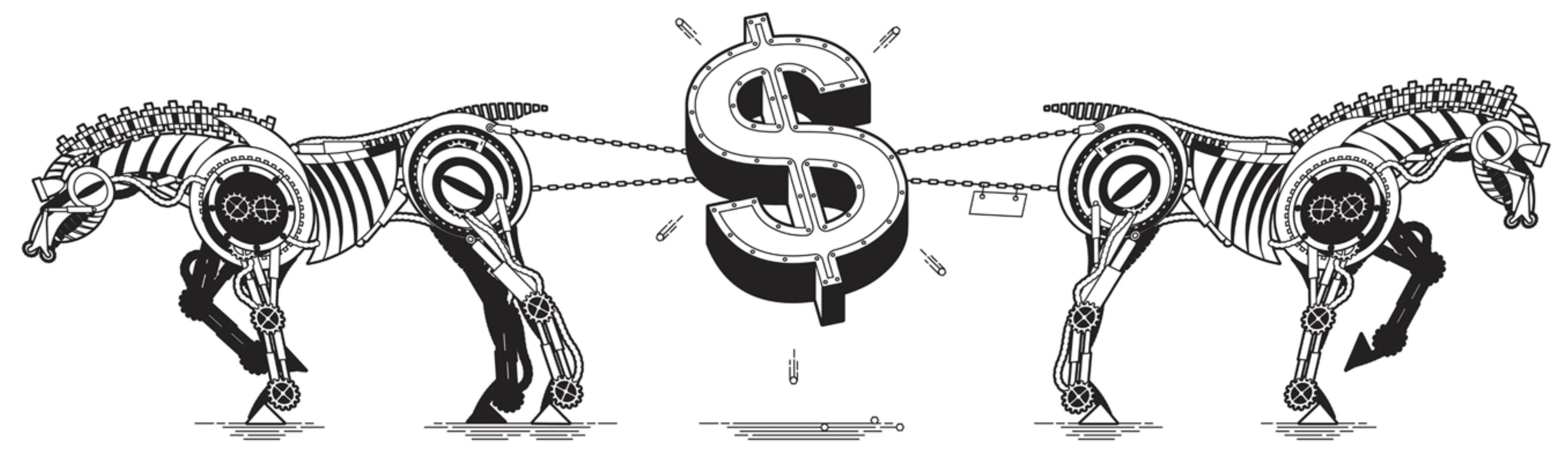

Luego de haber negado que existieran y duros y la experiencia de los consumidores estar de acuerdo con sancionar a los ban- de productos financieros niegan el paraiso en ellas ' ${ }^{2}$ en diciembre de la libre competencia que observa el sepasado, el presidente de la Asociación de ñor Sommerville.

Bancos Hernán Sommerville dijo que "era El año pasado, un informe del Institute posible" que la banca haya concedido cré- for Management Development puso a la

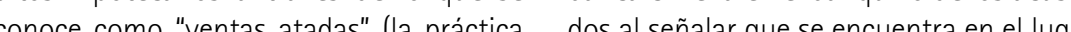
de un vendedor de condicioner la venta de 46 (de 57 paises) en el spread promedio un producto o servicio a compra de otro que cobra lo cual tendrí efectos negatiun procto o servicio). Del tono de sus palabras se desprendia que esto era casi un hecho aislado o, en el mejor de los casos sin mucha importancia, pues, de acuerdo a él, "nadie está obligado a tomar un crédito hipotecario. Los bancos dan la opción y esta es absolutamente voluntaria. Hay mucha competencia entre los bancos en Chile. Tambien señalo que quien se sienta incómodo, tiene la posibilidad de irse "al banco del frente, del lado o de más alla". Algo similar debe haber pensado la SuFinancieras cundo en noviembre autorizo ra venta coniunta en circunstancias que meses antes venia pronunciándose justamente por la idea contraria.

Mientras en el Congreso se ve el proyecto de ley que otorga atribuciones para

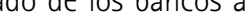
Sernac -una idea que provino de la propia que cobra, lo cual tendría efectos negativos en la competitividad del pais. La banca ya había estado sentada antes anquillo por el lento traspaso de la baja de tasas del Banco Central por las altas utilidades en un ano de crisis

fácil determinar el grado de competencia en una industria y el nivel de res sobros de culando las hay, hay

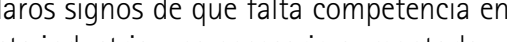
Primer Primer ejemplo. En 2003 regresé a Chile una cuenta corriente y después de haber a con de mi vida -o casi- y esperar alrededor de una semana cada vez, fui rechazado por dos bancos. El primer banco argumento que tenia una bajo rating en Dicom porque tenía más de cinco años sin movimientos financieros, lo cual era obvio dado e tiempo que llevaba fuera de Chile; la buena historia financiera anterior al parecer no servia de nada. El segundo banco me exigía en Chile sino que además es fija por trantres declaraciones de sueldo, pero como sa llevaba apenas un mes en Chile tenia una solamente y el contrato de trabajo indefnido que tenia no bastó. Al final logré abirir: una cuenta corriente a la manera chilen: Una amiga de un amigo que me conocia mi y conocia a un subgeren

ogró que me aprobaran.

Cuando volvi a vivir en Estados Unicorriente al llegar $y$ las diferencias coen banca en Chile fueron abismantes Lenéun formulario con información básica de apeas dos páginas y en menos de una hora tenía abierta la cuenta.

Segundo ejemplo. Tengo dos cuentas corrientes en el mismo banco en Chile. En ambas tengo tarjeta de credito y cuando intento pagar la deuda en dólares, el tipo de cambio es mucho más alto en una cuenta que en la otra. ¿Hay alguna explicación posible que no involucre poder de mercado y discriminacion de precios para algo as? Las veces que he solicitado una explicacion nalmente, las comisiones por el "uso de tarieta" dependen del monto de la compra ¿Por qué el costo para el banco de realizar una transacción depende del monto? Tampoco hay respuesta cuando pregunto. En tarjeta que tengo en mi cuenta en Estados Unidos la comisión no sólo es más baja que saccion

Terer jemplo. Pedi un crédito hipotecario en un banco distinto al mio y me oblgann abir una cuenta corriente en dicho alta: una forma disimulada de venta atada Todo el proceso de aprobación duró además casioce semana con estos ejemplos a pregunta obvia es por qué no me cambio de banco. to he hecho ya dos veces $y$ no hay muchas diferencias. El primer año as condiciones son mejores, pero luego hay cambios que dejan casi todo igual. La solución sería cambiarse de banco todos los años, pero eso es un costo de transaccion muy alto y dado todo el papeleo que desagradable.

La solución de fondo es introducir más intensidad en la competencia entre bancos: ello requiere probablemente cambios en algunas regulaciones y tal vez la introducción de otras que aumenten la transparencia, eliminen las ventas atadas, reduzcan comparación entre instituciones.

¿Por qué está regulado el horario de atención, por ejemplo? Siempre se ha dicho que la banca está regulada, así que no hay de qué preocuparse, pero la verdad es que solvencia de la banca y no la competen en la industria. Es asi como la Superintensa de la banca, codo a codo con la Asociacon de Bancos, cuando se intenta generar para los consumidores. El hecho de que los bancos quedaran

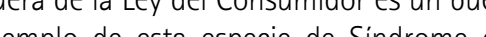
ha sufrido la Superintendencia la vuelta de carnero de la Supertendencia respecto al mismo tema de ventas atadas confirma las dudas respecto su verdadera indenendencia respecto a banca. Asi es dificil avanzar en generar Sernac Financiero vuelve a poner la disban a subir los costos de los créditos. Si un

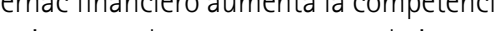
es cierto que los costos no van a bajar, pero

"Aqui no existen las ventas atadas, la "enta atada es ilegal y si alguien la hace de Noviembre. Funtan S www.emol.com/noticias/economia/detalle/ tallenoticias. asp?idnoticia $=448$ 